\title{
Continuous intravenous pentagastrin as a stimulant of maximal gastric acid secretion
}

\author{
M. C. MASON, G. R. GILES, AND C. G. CLARK ${ }^{1}$ \\ From the University Department of Surgery, The General Infirmary at Leeds
}

The synthetic gastrin-like pentapeptide (ICI 50, 123) may soon replace histamine as the standard stimulant of gastric secretion. As a diagnostic aid and for routine estimations a simple intramuscular test (Johnston and Jepson, 1967) may suffice. For research procedures, however, the rapid metabolism of the stimulant and the ability to produce a plateau of secretion give the intravenous infusion a considerable advantage. Difference of opinion exists as to the dose required to elicit a maximal response by this route (Konturek, 1967; Multicentre Studies, 1967; Wormsley, Mahoney, and $\mathrm{Ng}$, 1966). The present investigation was designed to determine such a dose in patients suffering from duodenal ulceration. In addition dose response relations were studied in patients who had previously been shown to have had a complete surgical vagotomy. A comparison was also made between the responses obtained with the optimal doses of pentagastrin before and after vagotomy and those obtained by a histamine infusion test (Lawrie, Smith, and Forrest, 1964).

\section{MATERIALS AND METHODS}

Fifteen male subjects with duodenal ulceration whose ages ranged from 19 to 63 years were investigated and all were aware of the nature of the study. Following an overnight fast a 12 or 14 FG nasogastric tube was passed and adjusted until a satisfactory position was obtained. Radiological screening was not employed. Secretions were obtained by continuous suction to pressures up to $60 \mathrm{~mm} \mathrm{Hg}$, and collected in 15-minute samples. Tubal patency was maintained by frequent air insufflation.

Basal collections were obtained for at least $\mathbf{4 5}$ minutes before the pentagastrin, made up in normal saline, was administered intravenously at a rate of $60 \mathrm{ml}$ per 15 minutes. Increasing dose levels of $0 \cdot 6,1 \cdot 2,3 \cdot 0$, and 6.0 $\mu \mathrm{g} / \mathrm{kg} / \mathrm{hr}$ were each infused for one hour. In seven experiments there was no interval between the end of one dose and the start of the next, whereas in the remaining eight a quarter of an hour was allowed to elapse between successive doses.

All samples were filtered through glasswool and a ${ }^{1}$ Present address: Department of Surgery, University College Hospital, London W.C.1.
$1 \mathrm{ml}$ aliquot from each was titrated against $\mathrm{N} / 100$ $\mathrm{NaOH}$, using Topfer's reagent (end point approximately $p \mathrm{H} \mathrm{3.5)}$ as indicator. The results were recorded as milliequivalents of 'free' acid per 15-minute period.

Using techniques identical with those described above an entirely different group of four female and 16 male patients were studied to compare the maximal acid secretion obtained with $0.4 \mu \mathrm{g} / \mathrm{kg} / \mathrm{hr}$ of constant intravenous histamine acid phosphate, and $1.2 \mu \mathrm{g} / \mathrm{kg} / \mathrm{hr}$ of similarly administered pentagastrin. All but four of the patients suffered from duodenal ulceration. The histamine test was covered by an intravenous injection of $\mathbf{5 0}$ mg mepyramine maleate (Anthisan) administered over a 10-minute period at the start of the histamine infusion, and was performed either on a different day, or at an interval of at least 45 minutes after the end of the pentagastrin infusion.

Ten male volunteers were investigated who had previously undergone vagotomy and drainage for duodenal ulcer. Postoperative insulin testing (Hollander, 1946) had indicated complete vagal gastric denervation in all cases, and at least three months had elapsed since operation. These patients all received increasing doses of pentagastrin at levels of $3.0,6 \cdot 0,12.0 \mu \mathrm{g} / \mathrm{kg} / \mathrm{hr}$ in a manner similar to that described in the first group of patients. A histamine infusion test was performed 30 minutes after the conclusion of the pentagastrin infusion.

In all cases the peak acid output has been derived by adding the results of the two highest consecutive 15minute samples and doubling this value to express the result as milliequivalents of free acid per hour.

\section{RESULTS}

Table I shows that in the seven cases where there was no interval between consecutive doses of pentagastrin the maximum gastric secretory response was achieved by a dose of $0.6 \mu \mathrm{g} / \mathrm{kg} / \mathrm{hr}$ in one instance and by $1.2 \mu \mathrm{g} / \mathrm{kg} / \mathrm{hr}$ in a further five. A dose of $6.0 \mu \mathrm{g} / \mathrm{kg} / \mathrm{hr}$ was required for patient $\mathrm{K}$., but the response here was only marginally greater than that obtained by $0.6 \mu \mathrm{g} / \mathrm{kg} / \mathrm{hr}$. Of the eight cases in which there was an interval between the doses, four gave maximal values at $0.6 \mu \mathrm{g} / \mathrm{kg} / \mathrm{hr}$, one at 1.2 $\mu \mathrm{g} / \mathrm{kg} / \mathrm{hr}$, and the remaining three at $3.0 \mu \mathrm{g} / \mathrm{kg} / \mathrm{hr}$. However, it can be seen in many cases that the 
T A B L E I

RESULTS IN SEVEN CASES RECEIVING PENTAGASTRIN WITH AND WITHOUT INTERVALS BETWEEN DOSES.

Patient Maximum Response to

\begin{tabular}{|c|c|c|c|c|c|}
\hline & $0.6 \mu \mathrm{g} / \mathrm{kg} / \mathrm{hr}$ & $1 \cdot 2 \mu \mathrm{g} / \mathrm{kg} / \mathrm{hr}$ & $3.0 \mu \mathrm{g} / \mathrm{kg} / \mathrm{hr}$ & $6.0 \mu \mathrm{g} / \mathrm{kg} / \mathrm{hr}$ & \\
\hline $\begin{array}{l}\text { A } \\
\text { B } \\
\mathbf{C} \\
\mathbf{D} \\
\mathbf{E} \\
\mathbf{F} \\
\mathbf{G} \\
\mathbf{H}\end{array}$ & $\begin{array}{l}31 \cdot 4 \\
42 \cdot 6 \\
32 \cdot 8 \\
39 \cdot 6 \\
31 \cdot 8 \\
36 \cdot 8 \\
23 \cdot 6 \\
24 \cdot 4\end{array}$ & $\begin{array}{l}31 \cdot 2 \\
38 \cdot 0 \\
29 \cdot 8 \\
36 \cdot 0 \\
25 \cdot 8 \\
36 \cdot 4 \\
28 \cdot 6 \\
29 \cdot 8\end{array}$ & $\begin{array}{l}34 \cdot 6 \\
33 \cdot 8 \\
29 \cdot 2 \\
46 \cdot 2 \\
31 \cdot 0 \\
35 \cdot 4 \\
32.6 \\
27 \cdot 0\end{array}$ & $\left.\begin{array}{l}31 \cdot 8 \\
36 \cdot 4 \\
28 \cdot 2 \\
46 \cdot 2 \\
31 \cdot 8 \\
35 \cdot 0 \\
32 \cdot 0 \\
24 \cdot 6\end{array}\right\}$ & $\begin{array}{l}\text { Interval between } \\
\text { doses }\end{array}$ \\
\hline $\begin{array}{l}\text { I } \\
\text { J } \\
\mathbf{K} \\
\mathbf{L} \\
\mathbf{M} \\
\mathbf{N} \\
\mathbf{O} \\
\text { Mean }\end{array}$ & $\begin{array}{l}23 \cdot 4 \\
45 \cdot 8 \\
29 \cdot 0 \\
30 \cdot 0 \\
18 \cdot 0 \\
32 \cdot 8 \\
42 \cdot 2 \\
32 \cdot 3\end{array}$ & $\begin{array}{l}43 \cdot 2 \\
57 \cdot 4 \\
24 \cdot 8 \\
31 \cdot 8 \\
23 \cdot 0 \\
34 \cdot 8 \\
35 \cdot 2 \\
33 \cdot 7\end{array}$ & $\begin{array}{l}38 \cdot 2 \\
47 \cdot 6 \\
20 \cdot 4 \\
27 \cdot 2 \\
23 \cdot 0 \\
33 \cdot 0 \\
39 \cdot 2 \\
33 \cdot 2\end{array}$ & $\left.\begin{array}{l}37 \cdot 8 \\
46 \cdot 0 \\
30 \cdot 4 \\
29 \cdot 4 \\
21 \cdot 4 \\
31 \cdot 0 \\
40 \cdot 4 \\
33 \cdot 5\end{array}\right\}$ & $\begin{array}{c}\text { No interval } \\
\text { between doses }\end{array}$ \\
\hline
\end{tabular}

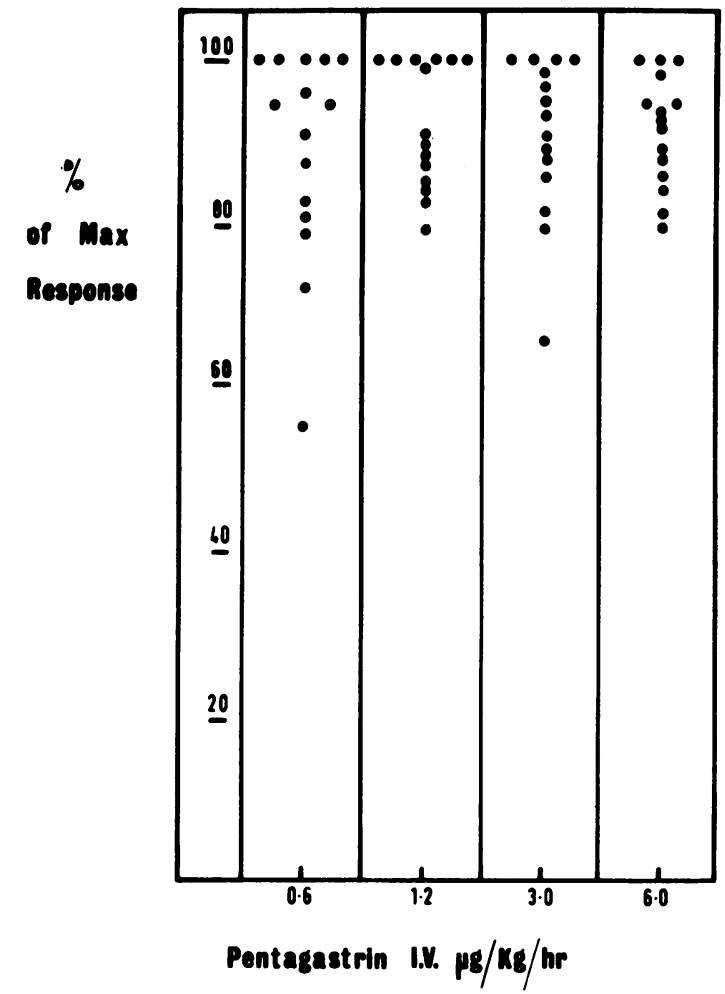

FIG. 1. Percentage of the maximal response produced by the varying doses of pentagastrin in the preoperative patients. response given by $3.0 \mu \mathrm{g} / \mathrm{kg} / \mathrm{hr}$ is less than that obtained from a smaller dose. This almost certainly reflects inadequacies of the technique. There appears to be no difference in the results obtained, whether an interval between increasing doses is employed, or not. The most remarkable feature is the close similarity between the overall mean values of the response produced by each of the four dose levels.

Figure 1 shows for each patient the percentage of the maximum response obtained at each dose level using the greatest value to define the maximum. For each dose the scatter of response is considerable, implying that no single level can be relied upon to provide a maximal output in every case. Indeed, a continuous intravenous infusion of pentagastrin can only be assumed to provide between $80 \%$ and $100 \%$ of a maximal response. This is as readily achieved with $1.2 \mu \mathrm{g} / \mathrm{kg} / \mathrm{hr}$ as with higher doses but infusion at a rate of $0.6 \mu \mathrm{g} / \mathrm{kg} / \mathrm{hr}$ fails to reach this in three of the 15 patients.

Table II shows a comparison between intravenous pentagastrin at $1.2 \mu \mathrm{g} / \mathrm{kg} / \mathrm{hr}$ and the histamine infusion test in the same individuals. Whilst certain minor discrepancies are evident in particular instances, overall there is a very good correlation $(r=0.940)$ between the acid output from pentagastrin and intravenous histamine. Statistical analysis does not reveal any significant difference between the responses obtained by these two stimulants and this is seen to be true both for the ulcer and non-ulcer groups of patients (Fig. 2).

Table III shows that after vagotomy greater concentrations of pentagastrin are required to achieve a maximum response and even a dose of $3.0 \mu \mathrm{g} / \mathrm{kg} / \mathrm{hr}$ of pentagastrin is inadequate as a 


\section{T A B L E I I}

RESULTS WITH PENTAGASTRIN AND HISTAMINE INFUSION TEST IN SOME SUBJECTS.

Maximum Acid Secretion (m-equiv/hr)

\begin{tabular}{lll} 
Patient & $\begin{array}{l}\text { Intravenous Histamine } \\
\text { Acid Phosphate } \\
(0.04 \mathrm{mg} / \mathrm{kg} / \mathrm{hr})\end{array}$ & $\begin{array}{l}\text { Intravenous Pentagastrin } \\
(1.2 \mathrm{\mu g} / \mathrm{kg} / \mathrm{hr})\end{array}$ \\
\hline
\end{tabular}

Duodenal Ulcer

$\begin{array}{lrr}\text { Group } & & \\ \text { A } & 64 \cdot 0 & 79 \cdot 8 \\ \text { B } & 20 \cdot 6 & 17 \cdot 0 \\ \text { C } & 15 \cdot 4 & 25 \cdot 2 \\ \text { D } & 54 \cdot 0 & 50 \cdot 8 \\ \text { E } & 24 \cdot 2 & 34 \cdot 0 \\ \text { F } & 31 \cdot 0 & 29 \cdot 0 \\ \text { G } & 49 \cdot 6 & 49 \cdot 6 \\ \text { H } & 25 \cdot 4 & 28 \cdot 6 \\ \text { I } & 60 \cdot 4 & 56 \cdot 4 \\ \text { J } & 36 \cdot 8 & 40 \cdot 4 \\ \text { K } & 47 \cdot 8 & 41 \cdot 0 \\ \text { L } & 46 \cdot 6 & 47 \cdot 4 \\ \text { M } & 37 \cdot 0 & 36 \cdot 6 \\ \text { N } & 52 \cdot 2 & 48 \cdot 2 \\ \text { O } & 36 \cdot 2 & 39 \cdot 2 \\ \text { P } & 51 \cdot 4 & 47 \cdot 2 \\ \text { Mean } & 40 \cdot 8 & 41 \cdot 9 \\ \text { SE } & 3 \cdot 7 & 3 \cdot 7 \\ \text { Non-ulcer } \text { Group } & & \\ \text { Q } & 28.6 & 29 \cdot 8 \\ \text { R } & 6 \cdot 8 & 8 \cdot 0 \\ \text { S } & 19 \cdot 0 & 15 \cdot 6 \\ \text { T } & 22 \cdot 2 & 24 \cdot 4\end{array}$

stimulant of maximum acid secretion in the completely vagotomized patient. Application of Student's $t$ test for paired values gives a highly significant difference $(P=<0.005)$ between the response obtained by $3.0 \mu \mathrm{g} / \mathrm{kg} / \mathrm{hr}$ and $6.0 \mu \mathrm{g} / \mathrm{kg} / \mathrm{hr}$. A dose of $12.0 \mu \mathrm{g} / \mathrm{kg} / \mathrm{hr}$ is seen to be superior to $6.0 \mu \mathrm{g} / \mathrm{kg} / \mathrm{hr}$ in two cases, and to produce an identical secretion in a further two instances. Conversely, the latter level is clearly the more effective in the remaining six individuals. Statistical analysis of the paired results shows no significant difference between these two doses $(P=>0.05)$.

Similar to the findings in the first group of patients, again no single dose of pentagastrin gives a maximal response in all cases. Therefore, in the precence of a complete vagotomy, a dose of $6.0 \mu \mathrm{g} / \mathrm{kg} / \mathrm{hr}$ would seem to be optimal. Figure 3 compares the results obtained in the same patients by stimulation with pentagastrin at $6.0 \mu \mathrm{g} / \mathrm{kg} / \mathrm{hr}$ and histamine 0.04 $\mu \mathrm{g} / \mathrm{kg} / \mathrm{hr}$. There is a good correlation $(\mathrm{r}=0.946)$, and statistically no significant difference between the secretory responses to the two stimulu.

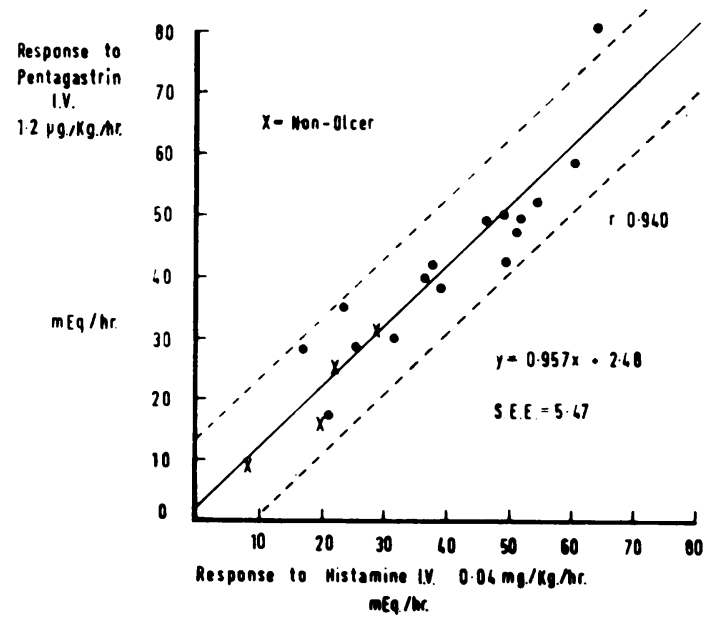

FIG. 2. Preoperative comparison of the response to pentagastrin and to histamine acid phosphate.

It must be emphasized that Tables I, II, and III refer to different groups of patients.

SIDE EFFECTS Side effects about which the patients spontaneously complained were recorded, and, in addition, each was directly questioned on this subject. At a dose of $1.2 \mu \mathrm{g} / \mathrm{kg} / \mathrm{hr}$ no side effects of any type were detected but of the 25 patients who

T A B L E II I

RESULTS IN PATIENTS AFTER VAGOTOMY

\begin{tabular}{|c|c|c|c|c|}
\hline \multirow[t]{2}{*}{ Patient } & \multicolumn{3}{|c|}{ Maximum Response with } & \multirow{2}{*}{$\begin{array}{l}\text { Maximum Response with } \\
\text { Histamine } A P\end{array}$} \\
\hline & $3.0 \mu \mathrm{gg} / \mathrm{kg} / \mathrm{hr}$ & $6.0 \mathrm{\mu g} / \mathrm{kg} / \mathrm{hr}$ & $12.0 \mu \mathrm{g} / \mathrm{kg} / \mathrm{hr}$ & \\
\hline $\begin{array}{l}\mathbf{A} \\
\mathbf{B} \\
\mathbf{C} \\
\mathbf{D} \\
\mathbf{E} \\
\mathbf{F} \\
\mathbf{G} \\
\mathbf{H} \\
\mathbf{I} \\
\mathbf{J} \\
\text { Mean } \\
\text { SE }\end{array}$ & $\begin{array}{c}1.6 \\
10.0 \\
0 \\
18.8 \\
17.6 \\
15.6 \\
1.2 \\
0 \\
31 \cdot 2 \\
16.0 \\
11.2 \\
3.3\end{array}$ & $\begin{array}{r}2.2 \\
12 \cdot 2 \\
0 \\
24.6 \\
21 \cdot 2 \\
17.4 \\
4.2 \\
2.6 \\
32.0 \\
17.6 \\
13.4 \\
3.5\end{array}$ & $\begin{array}{r}3.2 \\
10.2 \\
0.8 \\
23.2 \\
19.8 \\
17.4 \\
3.6 \\
2.6 \\
29.8 \\
16.4 \\
12.7 \\
3.2\end{array}$ & $\begin{array}{r}2.4 \\
10.8 \\
0.6 \\
18.8 \\
28 \cdot 0 \\
17.2 \\
4.4 \\
1.8 \\
26 \cdot 6 \\
19.2 \\
13.0 \\
3.3\end{array}$ \\
\hline
\end{tabular}

Expressed as m-equiv/hr of free acid. 


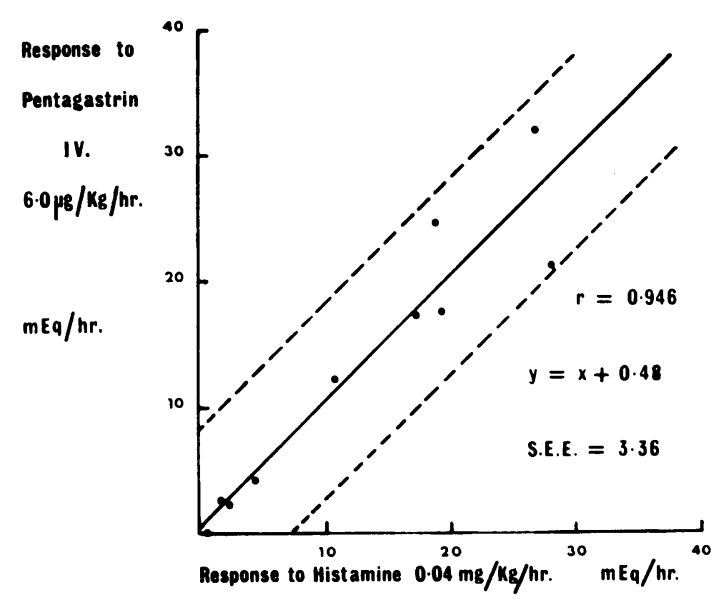

FIG. 3. Comparison of the response to pentagastrin and to histamine acid phosphate after complete surgical vagotomy.

received doses greater than this, two complained of a marked nausea which was transient and occurred at the start of the infusion of $6.0 \mu \mathrm{g} / \mathrm{kg} / \mathrm{hr}$. In another patient, whose results could not be recorded in this paper, the severe nausea and vomiting during infusion of the $6.0 \mu \mathrm{g} / \mathrm{kg} / \mathrm{hr}$ dose, resulted in the test having to be abandoned.

A single patient complained of an intermittent abdominal colic at doses above $3.0 \mu \mathrm{g} / \mathrm{kg} / \mathrm{hr}$ and another experienced a particularly strong urge to defaecate when the dose level was $6.0 \mu \mathrm{g} / \mathrm{kg} / \mathrm{hr}$.

\section{DISCUSSION}

The present investigation confirmed the observations of Wormsley and Mahoney (1967) and showed that $0.6 \mu \mathrm{g} / \mathrm{kg} / \mathrm{hr}$ of pentagastrin gave a maximum response in many cases, but there was no single dose which gave a maximal output in every case. The Multicentre Study (1967) suggested that a dose of $6.0 \mu \mathrm{g} / \mathrm{kg} / \mathrm{hr}$ was necessary to obtain the maximal response when the intravenous infusion technique was used, whereas Konturek (1967) believed 1.2 $\mu \mathrm{g} / \mathrm{kg} / \mathrm{hr}$ was sufficient. We found that only one patient needed $6.0 \mu \mathrm{g} / \mathrm{kg} / \mathrm{hr}$ and in this instance the response was only marginally greater than that obtained with a dose 10 times smaller. This suggested that $6.0 \mu \mathrm{g} / \mathrm{kg} / \mathrm{hr}$ was unnecessarily high. Furthermore there appeared to be no advantage in using $3.0 \mu \mathrm{g} / \mathrm{kg} / \mathrm{hr}$ as both the mean and scatter of the results at this level did not differ from that obtained with $1.2 \mu \mathrm{g} / \mathrm{kg} / \mathrm{hr}$. It was therefore concluded that, when given by a constant intravenous infusion, a dose of $1.2 \mu \mathrm{g} / \mathrm{kg} / \mathrm{hr}$ of pentagastrin was optimal for patients with intact innervation. At such a dose, side effects were also avoided.

In these studies it was not possible to demonstrate the increased acid output which Konturek (1967) claimed occurred with pentagastrin when compared with histamine. His results were calculated from the peak 15-minute sample but study of the coefficients of variation of the present data suggested the peak 30minute output was the more reliable basis for derivation of the maximal hourly response. Even so, when the peak 15-minute output is used, the difference in response between pentagastrin and histamine does not approach statistical significance. It was concluded that pentagastrin at a dose of $1.2 \mu \mathrm{g} / \mathrm{kg} / \mathrm{hr}$ caused a maximal output of gastric acid similar to that produced by a standard histamine infusion test (Lawrie et al, 1964).

In the group of patients who were examined after a complete surgical vagotomy, the overall findings tended to support the results of the Multicentre Study (1967). Slight differences in technique were present, however, and some of the patients in the present study were investigated more than 18 months after surgery. The behaviour of the stomach in response to stimulation by pentagastrin under these circumstances may not be identical with that found in the immediate postoperative period. Essentially, there was agreement with the Multicentre Study (1967) that a higher dose of pentagastrin was needed to produce maximal acid secretion after complete gastric vagal denervation, but there was a difference in that a dose level of $6 \cdot 0 \mu \mathrm{g} / \mathrm{kg} / \mathrm{hr}$ appeared adequate. The importance lies in the fact that had $12.0 \mu \mathrm{g} / \mathrm{kg} / \mathrm{hr}$ been necessary, an increased incidence of unpleasant side effects would have been expected. Furthermore the cost, in economic terms, of using commercially available pentagastrin would have become substantially greater.

There was a good correlation between the responses to the optimal doses of pentagastrin and histamine, both in patients with intact and divided vagi. Hence, although it was not possible to present pre- and postoperative secretory data in the same patients, by inference it can be suggested that the reduction in acid secretion, brought about by surgical vagotomy, is likely to be of the same order for both stimulants. This is at variance with the studies of Konturek (1967), who noted a substantially greater reduction in the pentagastrinstimulated acid than in that stimulated by histamine. In his postvagotomy studies, however, he used a dose of $1.2 \mu \mathrm{g} / \mathrm{kg} / \mathrm{hr}$ of pentagastrin which has been shown to give a submaximal stimulus. Konturek (1967) found a reduction of the intravenous histamine response of only $30 \%$ which is considerably 
less than the 60 to $65 \%$ usually observed after complete vagotomy in our experience.

Bank, Marks, Louw, and Tigler-Wybrandi (1967) compared the response to subcutaneous pentagastrin at a dose of $6.0 \mu \mathrm{g} / \mathrm{kg}$ and an augmented histamine test in postvagotomy patients, and found an increased response to pentagastrin which was significantly higher. The results of the present study and those of the Multicentre Study (1967) do not support this conclusion, and this may be explained by the fact that subcutaneous and intravenous techniques are not strictly comparable. Williamson, Hume, and Weyers (1967), who studied the responses to histamine and pentagastrin given subcutaneously, found no significant difference between the mean peak acid outputs either preoperatively or postoperatively.

\section{SUMMARY}

The effects of graded doses of pentagastrin, administered by a constant intravenous infusion, have been studied in patients before surgery for duodenal ulceration, and in another similar group of patients several months after complete vagotomy and drainage, to determine the dose required to elicit maximal gastric acid secretion in each instance. In the preoperative patients, a dose of $1.2 \mu \mathrm{g} / \mathrm{kg} / \mathrm{hr}$ was found to be adequate but, after a complete surgical vagotomy, it was necessary to increase the dose to $6.0 \mu \mathrm{g} / \mathrm{kg} / \mathrm{hr}$ to obtain the maximum output. At these levels, the responses obtained compared favourably with those obtained from a standard histamine infusion test.

We are grateful to Professor J. C. Goligher for his advice and assistance in this work. We wish to thank Dr J. D. Fitzgerald, ICI Pharmaceuticals Division, for his help and in particular for his gift of ICI 50, 123. Miss S. Halloway gave valuable technical assistance.

\section{REFERENCES}

Bank, S., Marks, I. N., Louw, J. H., and Tigler-Wybrandi, N. (1967) Stimulation of gastric-acid secretion by histamine, pentagastrin, and pentagastrin-propantheline after vagotomy in man. Lancet, 2, 67-69.

Hollander, F. (1946). The insulin test for the presence of intact nerve fibers after vagal operations for peptic ulcer. Gastroenterology, 7, 607-614.

Johnston, D., and Jepson, K. (1967). Use of pentagastrin in a test of gastric acid secretion. Lancet, $2,585-588$.

Konturek, S. J. (1967). Gastrin-like pentapeptide ICI 50, 123: a potent gastric stimulant in man. Amer. J. dig. Dis., 12, 285-292.

Lawrie, J. H., Smith, G. M. R, and Forrest, A. P. M. (1964). The histamine-infusion test. Lancet, 2, 270-273.

Multicentre Pilot Study (1967). Pentagastrin as a stimulant of maximal gastric acid response in man. Ibid., 1, 291-295.

Multicentre Study (1967). The effect of vagotomy on gastric secretion elicited by pentagastrin in man. Ibid., 2, 534-536.

Williamson, J. M., Hume, R., and Weyers, E. M. (1967). Effect of pentagastrin after vagotomy. Ibid., $2,941$.

Wormsley, K. G., and Mahoney, M. P. (1967). Parietal cell responsiveness in duodenal ulcer. Brit. med. J., 1, 278.

- - _ (ICI 50, 123) on stomach and pancreas. Lancet, 1, 993-996. 